\title{
Residual antiseptic efficacy of octenidine dihydrochloride versus chlorhexidine gluconate in alcoholic solutions
}

\author{
FHH Brill ${ }^{1 *}$, N Radischat ${ }^{2}$, P Goroncy-Bermes ${ }^{2}$, J Siebert ${ }^{2}$ \\ From 3rd International Conference on Prevention and Infection Control (ICPIC 2015) \\ Geneva, Switzerland. 16-19 June 2015
}

\section{Introduction}

Skin antisepsis is an important measure to prevent postoperative infections. It is known that wound infections infringe the well-being of the patient and prolongs the rehabilitation significantly. At the same time additional costs will be caused in the health care system. Alcohol-based solutions containing the active ingredients chlorhexidine gluconate $[\mathrm{CHX}]$ or octenidine dihydrochloride $[\mathrm{OCT}]$ have a residual antimicrobial effect on skin. This may re-sult in a better preventative outcome than alcohol alone.

\section{Objectives}

The aim of the presented study was to compare the immediate and long-term efficacy of CHX and OCT.

\section{Methods}

We performed a study on the skin on the arm of 20 healthy volunteers in a cross-over design based on DGHM-standard method 13 and measured the colony forming units $(\mathrm{cfu})$ of the resident skin flora after the application of the products according to Williamson and Kligman (1965). The cfu were determined directly after the application and after $24 \mathrm{~h}$ on 5 consecutive study days. The calculated log reduction factors were statistically evaluated with the student's t-test.

\section{Results}

Both solutions showed as expected a significant any quick reduction of the resisdent skin flora and a longterm effect over $24 \mathrm{~h}$. For OCT a statistically significant superior long-term effect after four applications was determined (lg reduction: (2.21 vs. 1.37; $\mathrm{p}=0.004)$.

\footnotetext{
1Dr. Brill + Partner GMBH Instiute for Hygiene and Microbiology, Hamburg, Germany

Full list of author information is available at the end of the article
}

\section{Conclusion}

The presented data show that alcoholic solutions with octenidin dihydrochloride and chlorhexidine gluconate show a comparable efficacy on the resident skin flora. Alcohol-based preparations with the additional active octenidin dihydrochloride are a valid alternative for skin antisepics to the world-wide broadly used CHX-based products.

\section{Disclosure of interest}

F. Brill Grant/Research support from: partially by Schülke \& Mayr, Germany., N. Radischat Employee of: Schülke \& Mayr, Germany., P. Goroncy-Bermes Employee of: Schülke \& Mayr, Germany., J. Siebert Employee of: Schülke \& Mayr, Germany.

\section{Authors' details \\ ${ }^{1}$ Dr. Brill + Partner GMBH Instiute for Hygiene and Microbiology, Hamburg, Germany. ${ }^{2}$ Research \& Development, Schülke \& Mayr GmbH, Norderstedt, Germany.}

Published: 16 June 2015

\section{doi:10.1186/2047-2994-4-S1-P33}

Cite this article as: Brill et al.: Residual antiseptic efficacy of octenidine dihydrochloride versus chlorhexidine gluconate in alcoholic solutions. Antimicrobial Resistance and Infection Control 2015 4(Suppl 1):P33. 